\title{
Dynamic variability in F-region ionospheric composition at auroral arc boundaries
}

\author{
M. Zettergren ${ }^{1, *}$, J. Semeter ${ }^{2}$, B. Burnett ${ }^{2}$, W. Oliver ${ }^{2}$, C. Heinselman ${ }^{3}$, P.-L. Blelly ${ }^{4}$, and M. Diaz ${ }^{5}$ \\ ${ }^{1}$ Physical Sciences Department, Embry-Riddle Aeronautical University, Daytona Beach, FL, USA \\ ${ }^{2}$ Department of Electrical and Computer Engineering and Center for Space Physics, Boston University, Boston, MA, USA \\ ${ }^{3}$ SRI International, Menlo Park, CA, USA \\ ${ }^{4}$ CESR, Toulouse, France \\ ${ }^{5}$ Electrical Engineering Dept., College of Engineering, University of Chile, Santiago, Chile \\ * formerly at: Department of Electrical and Computer Engineering and Center for Space Physics, Boston University, Boston, \\ MA, USA
}

Received: 6 October 2009 - Revised: 20 January 2010 - Accepted: 15 February 2010 - Published: 25 February 2010

\begin{abstract}
The work presents a data-model synthesis examining the response of the auroral F-region ion temperature, composition, and density to short time scale $(<1 \mathrm{~min})$ electric field disturbances associated with auroral arcs. Ion temperature profiles recorded by the Sondrestrom incoherent scatter radar (ISR) are critically analyzed with the aid of theoretical calculations to infer ion composition variability. The analyses presented include a partial accounting for the effects of neutral winds on frictional heating and show promise as the groundwork for future attempts to address ion temperature-mass ambiguities in short-integration ISR data sets. Results indicate that large $\mathrm{NO}^{+}$enchancements in the F-region can occur in as little as $20 \mathrm{~s}$ in response to impulsive changes in ion frictional heating. Enhancements in molecular ion density result in recombination and a depletion in plasma, which is shown to occur on time scales of several minutes. This depletion process, thus, appears to be of comparable importance to electrodynamic evacuation processes in producing auroral arc-related plasma depletions. Furthermore, the potential of ionospheric composition in regulating the amounts and types of ions supplied to the magnetosphere is outlined.
\end{abstract}

Keywords. Ionosphere (Auroral ionosphere; Ion chemistry and composition; Ionosphere-magnetosphere interactions)

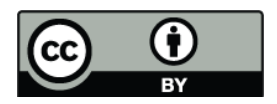

Correspondence to: M. Zettergren (zettergm@erau.edu)

\section{Introduction}

Electric fields are a ubiquitous feature of the high latitude ionosphere. Auroral arcs, in particular, are associated with strong perpendicular electric fields (Marklund, 1984; Johnson et al., 1998), often localized at arc boundaries (e.g. Evans et al., 1977; Opgenoorth et al., 1990). Auroral electric fields arise due to ionospheric/magnetospheric convection channels which lead to the formation of the arc (Lyons, 1992), or polarization effects which are sometimes observed near the edges of auroral arcs, where conductivity gradients are strong (de La Beaujardiere et al., 1977; Evans et al., 1977).

Auroral electric fields significantly influence densities, temperatures, and composition in the ionosphere (e.g. Rodger et al., 1992). Electric fields drive the ionospheric plasma through the neutral atmosphere and cause intense ion frictional heating. Resulting high ion temperatures can drastically modify ion chemical reaction rates and generally favor conversion of $\mathrm{O}^{+}$to $\mathrm{NO}^{+}$(McFarland et al., 1973; Torr et al., 1977; St.-Maurice and Torr, 1978; St.-Maurice and Laneville, 1998) through the reaction:

$\mathrm{O}^{+}+\mathrm{N}_{2} \longrightarrow \mathrm{NO}^{+}+\mathrm{N}$

This acts to raise the molecular to atomic ion transition altitude (where the plasma is composed of $50 \% \mathrm{O}^{+}$and $50 \%$ molecular ions) above its quiescent value. Modeling studies by Schunk et al. (1975); Diloy et al. (1996) have shown that, in steady-state situations, the molecular to atomic ion transition altitude may be increased to $>280 \mathrm{~km}$ by electric field-induced frictional heating. In some extreme cases $\mathrm{NO}^{+}$ may even become the dominant F-region ion (Schunk et al., 1975; Lathuillère and Kofman, 2006). In regions where $\mathrm{O}^{+}$

Published by Copernicus Publications on behalf of the European Geosciences Union. 
has been converted to $\mathrm{NO}^{+}$, ionization depletions form since chemical lifetimes are much shorter for molecular ions (e.g. Banks and Kockarts, 1973). Ionospheric features noted in these modeling studies have been corroborated by various observational case studies (Kelly and Wickwar, 1981; Lathuillere, 1987; Haggstrom and Collis, 1990) and combined observational and modeling efforts (Lathuillere et al., 1997).

To date, the most common observational technique for studying ion composition is incoherent scatter radar (ISR). ISR is one of the most powerful remote sensing tools for examining the high latitude ionosphere. Transmitted radio waves are scattered by the ionospheric plasma and received by the ISR. The received signal covers a spectrum of frequencies, and ionospheric plasma parameters are estimated by fitting this IS spectrum to a theoretical model. Roughly speaking, the spectral width of the ion line component of the IS spectrum yields an estimate of $T_{i} / m_{i}$ (ion temperature to mass ratio), the ion line peak to valley ratio gives $T_{e} / T_{i}$ (electron to ion temperature ratio), the bulk ion line doppler shift gives $v_{i}$ (line-of-sight ion drift), and the total scattered power gives $n_{e}$ (electron density). Unless extremely high quality data exist, ion composition must be assumed in order to compute absolute ion and electron temperatures (Evans, 1969; Oliver, 1979; Lathuillere et al., 1983). At the Sondrestrom ISR facility, a static model of ion composition-vs.-altitude is used to process IS spectra.

There has been much progress in recent years in mitigating ion temperature-mass ambiguities in IS spectra. Most of these methods rely on reduced-parameter descriptions of the ionospheric density, temperatures, and composition, vs. altitude which are extensions of the method developed by Oliver (1979). The diurnal (Cabrit and Kofman, 1997) and seasonal (Litvin et al., 1998; Shibata et al., 2000) variability in ion composition at high latitudes has been explored and wellcharacterized using such techniques. When the ionosphere is severely disturbed by electric fields the reliable analysis of ISR data becomes extremely difficult (e.g. Lathuillère and Kofman, 2006). Methods to address these problems rely on specifying either the electron temperature (Kelly and Wickwar, 1981) or ion temperature (Haggstrom and Collis, 1990) via a model or assumption and then fitting IS spectra for composition.

A final complication in the analysis of ISR spectra is that significant ion temperature anisotropies are known to occur at high latitudes (Raman et al., 1981; Hubert and Lathuillere, 1989; Lathuillere et al., 1991). The ISR analysis technique has been adapted by several authors to take this anisotropy into account (Gaimard et al., 1996; Hubert et al., 1997). Anisotropies in the presence of large electric fields require that both parallel and perpendicular temperatures be estimated when analyzing ion temperatures in auroral regions. In this study, all observations presented were recorded with the radar pointing parallel to the local magnetic field. Thus the temperature of interest for this work is the field-parallel temperature.
This paper focusses on the response of high-latitude Fregion ion composition to dynamic (short time scale) electric field disturbances. As outlined above, it is well-established that molecular ion enhancements occurs as a result of ion frictional heating by electric fields (e.g. Lathuillere et al., 1983; Haggstrom and Collis, 1990). However, due to observational limitations, there is little information currently available about the extent of composition variability on time scales of less than one minute. Short time scale responses are important in discerning how ionospheric composition may regulate the types and amounts of ions sourced to the magnetosphere, as ion outflow is known to occur during dynamic auroral events (e.g. Moore and Horwitz, 2007). Such scenarios are relevant to substorm expansion and situations where steadily convecting plasma suddenly encounters a region of variable electric field or conductivity.

Ion composition variability is inferred in this work through ion temperature profile shapes observed by standard ISR analysis routines. Artifacts in ion temperature profiles have been noted before as being indicative of a wrong ion composition assumption in the ISR fitter (Shibata et al., 2000; Oyama et al., 2004), but this research undertakes a critical data-model comparison of the temperature profiles. This approach clearly illustrates profile features that can be taken as evidence of composition variability and certain pitfalls in interpreting these features. This work also makes use of a statistical database of Sondrestrom measurements, which are an underutilized resource for studying ion composition. In the analysis presented herein, careful attention is given to the effects of horizontal neutral winds on temperature profiles and ion composition.

\section{Observed ion temperature profiles at auroral boundaries}

Combined camera and incoherent scatter radar (ISR) measurements routinely carried out at the Sondrestrom research facility are ideal for examining F-region energy balance near auroral arcs. Cameras provide context about the shape, location, and intensity of auroral forms, while ISR gives information about the state of the ionospheric plasma (Semeter et al., 2005; Zettergren et al., 2008).

Ion temperature profiles recorded by the Sondrestrom ISR on 26 February 2001 03:20-03:40 UT show clear evidence of ion frictional heating expected near auroral arc boundaries. For this experiment the Sondrestrom ISR was operating in dwell mode in the magnetic zenith. A $160 \mu$ s pulse was used, the scattered returns were integrated for $30 \mathrm{~s}$, and IS spectra were formed and then fitted to obtain $n_{e}, T_{i}, T_{e}$, and $v_{i}$. A static ion composition profile was used in the fitting process (see later discussion associated with Fig. 5). For most of this case study period, a faint $\left(\sim 0.5 \mathrm{~mW} \mathrm{~m}^{-2}\right)$ auroral arc was stationary just to the south of the Sondrestrom ISR field of view as shown in panel (a) of Fig. 1. Concurrent 

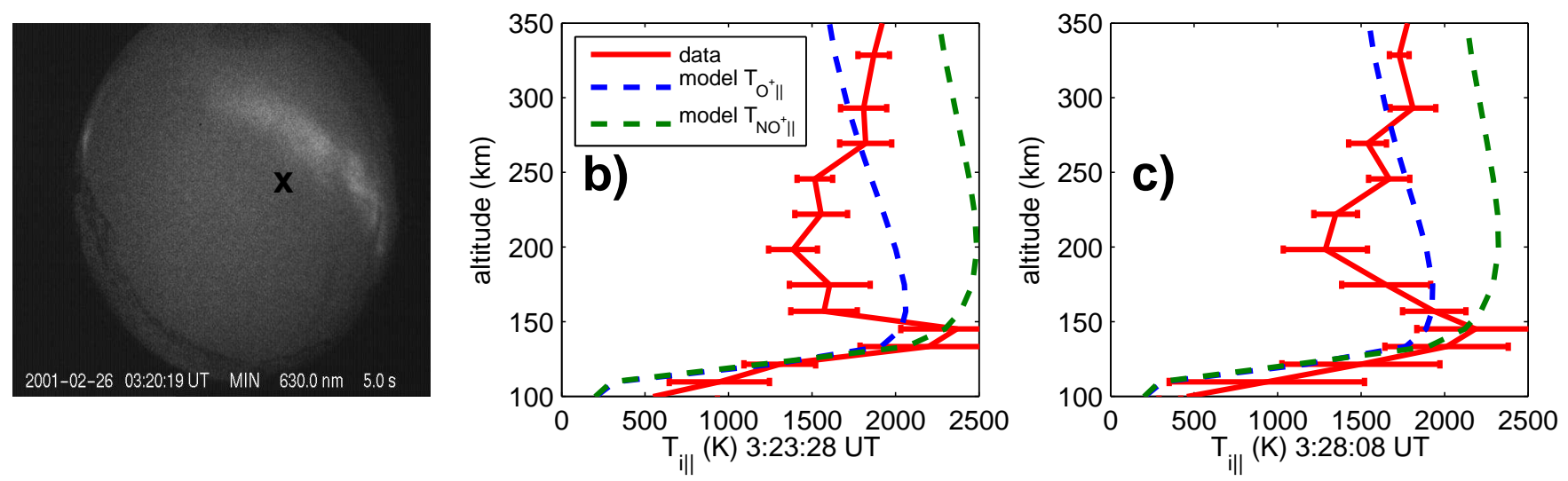

Fig. 1. Auroral forms and associated ion temperature profiles for 26 February 2001. Panel (a) Aurora in $630 \mathrm{~nm}$ emissions recorded by the allsky camera at Sondrestrom at 03:20:19 UT. The approximate radar beam pointing position is indicated by an X in the image. Panels (b) and (c) Ion temperature estimated by the Sondrestrom ISR at various times during the observational period.

ion drift measurements from the SUPERDARN Stokkseyri radar showed a strong shear in line-of-sight (westward) convection velocity in the vicinity of the auroral arc. Thus, this data set is ideal for observing the effects of arc-related electric fields on ion composition.

Solid lines (with error bars) in panels (b) and (c) of Fig. 1 show examples of ion temperature profiles observed adjacent to the auroral arc, where electric fields were large. These profiles display typical characteristics of ion temperatures observed throughout the 03:20-03:40 UT time interval. The effects of frictional heating are clearly visible as the ion temperatures are elevated far above their quiescent nighttime value (about $1000 \mathrm{~K}$ above $200 \mathrm{~km}$ altitude). Temperatures profiles recorded during this experiment exhibit a large amount of vertical spatial structure. The profiles tend to show a localized maximum around $150 \mathrm{~km}$ altitude, a sharp negative gradient from $\sim 150-200 \mathrm{~km}$, and a local minimum at $\sim 200 \mathrm{~km}$. The temperature is then relatively constant from $\sim 200-250 \mathrm{~km}$, and has a positive gradient from $\sim 250$ $300 \mathrm{~km}$. This characteristic profile shape is hereafter referred to as an ion temperature inversion. It is worth emphasizing that the ISR does not directly observe ion temperature, so these inversions could be an artifact of the spectral processing, as discussed below.

Anomalous features in ion temperature profiles have been previously noted as being a result of a wrong fitter composition model, in the particular case of small disturbance electric fields (Oyama et al., 2004). The data of Fig. 1, however, are recorded during a time when the electric field is obviously quite large as indicated by the high E-region ion temperatures and evidence of Farley-Buneman instability (Schlegel and St.-Maurice, 1981) in concurrent electron temperature data (not shown). Here a theoretical model of ion frictional heating is used to explicitly test the idea that these profile features are consistent with dynamically variable composition.
Ion temperature at high latitudes is controlled by ion frictional heating from $\boldsymbol{E}_{\perp} \times \boldsymbol{B}$ drift of the ionospheric plasma and heat exchange with the neutral atmosphere (Banks and Kockarts, 1973; St.-Maurice and Hanson, 1982). Below $\sim 350 \mathrm{~km}$ ion momentum and energy balance equations may be simplified to yield an expression for the parallel ion temperature (cf. St.-Maurice et al., 1999).

$T_{\mathrm{s} \|}=T_{\mathrm{n}}+\frac{3}{2} \beta_{\mathrm{s} \|} \frac{\left\langle m_{\mathrm{n}}\right\rangle}{3 k_{\mathrm{B}}} \frac{1}{1+\left(v_{\mathrm{s}} / \omega_{\mathrm{s}}\right)^{2}}\left(\frac{E_{\perp}^{\prime}}{B}\right)^{2}$

In Eq. (2), the subscript "s" refers to the ion species of interest, $T_{\mathrm{n}}$ is the neutral temperature, $\beta_{\|}$is a collision-typedependent coefficient (Winkler et al., 1992; McCrea et al., 1993) which describes temperature anisotropies, $\left\langle m_{\mathrm{n}}\right\rangle$ is an average mass of the neutral atmospheric constituents (cf. Winkler et al., 1992), $k_{\mathrm{B}}$ is the Boltzmann constant, $v_{\mathrm{S}}$ is the ion-neutral collision frequency, and $\omega_{\mathrm{s}}$ is the gyro-frequency. $E_{\perp}^{\prime}$ is the effective electric field strength (the electric field in a frame of reference drifting with the neutral gas), given by:

$\boldsymbol{E}_{\perp}^{\prime}=\boldsymbol{E}_{\perp}+\boldsymbol{u}_{\mathrm{n} \perp} \times \boldsymbol{B}$,

where $\boldsymbol{B}$ is the geomagnetic field and $\boldsymbol{u}_{n \perp}$ is the perpendicular neutral wind drift velocity. Neutral atmospheric parameters for evaluating Eq. (2) are taken from the NRLMSISE00 model (Picone et al., 2002), and the $\beta_{\|}$factor is taken from theoretical calculations by Winkler et al. (1992). Using these quantities, the ion temperature profiles for each species may be modeled from Eq. (2) as a function of the effective electric field. Under conditions of strong frictional heating, the temperatures for each ion species will be different due to different types of collisional interactions (polarization vs. charge exchange) that dominate for each species (St-Maurice and Schunk, 1979). 
The collision frequency used in Eq. (2), $v_{\mathrm{s}}$, is a summation over collisions of ion species "s" with each constituent of the neutral atmosphere (denoted with subscript "n").

$v_{\mathrm{s}} \equiv \sum_{\mathrm{n}} v_{\mathrm{sn}}$

In the F-region ionosphere the relevant colliding species are $\mathrm{s}=\mathrm{NO}^{+}, \mathrm{O}^{+}$and $\mathrm{n}=\mathrm{N}_{2}, \mathrm{O}_{2}, \mathrm{O}$. The collision frequencies for each of these interactions are taken from Schunk and Nagy (2000). As outlined in the introduction of Oliver and Glotfelty (1996) there has been much debate in the literature regarding the value of the $\mathrm{O}^{+}-\mathrm{O}$ collision frequency. The standard value of this collision frequency has, in the past, been based on the work of Banks (1966). Many studies (Burnside et al., 1987; Salah, 1993; Buonsanto et al., 1997) suggest that this standard value be modified by a multiplicative factor greater than one. However, there is also some evidence indicating that the multiplicative adjustment should be effectively less than one (Oliver and Glotfelty, 1996). Hence, there is no consensus on the $\mathrm{O}^{+}-\mathrm{O}$ collision. Fortunately, this uncertainly does not affect the current study greatly. In particular, the analysis of E-region temperatures, to be described shortly, is unaffected due to the absence of $\mathrm{O}^{+}$at these altitudes.

The effective electric field corresponding to the two profiles in Fig. 1 may be estimated from E-region ion temperatures at these times. In the E-region $(<150 \mathrm{~km}$ altitude), the ions are molecular, and the fitter ion composition correct. Therefore, E-region temperature measurements may be used with Eq. (2) to estimate $E_{\perp}^{\prime}$. Note that this method implicitly takes the effects of the neutral wind into account (see Eq. 3), as opposed to a direct calculation of the electric field through plasma drifts measured from the Sondrestrom 3-position mode. This point is critical for analysis of temperatures and composition at high latitudes where winds can be substantial during storms (Richmond and $\mathrm{Lu}, 2000$ ) and near discrete auroral features (St.-Maurice and Schunk, 1981; Eastes et al., 1992). Furthermore, the neutral wind at high latitudes can be quite structured (Aruliah et al., 2004), which also poses problems for analysis of ion temperature data with the 3-position mode at Sondrestrom. The method of estimating $E_{\perp}^{\prime}$ from temperature does require the assumption that $E_{\perp}^{\prime}$ (and, thus, the horizontal neutral wind) does not change with altitude. Under this assumption, there is one unknown $\left(E_{\perp}^{\prime}\right)$ to solve for using reliable $T_{i \|}$ measurements from $133 \mathrm{~km}$ and $145 \mathrm{~km}$. A weighted least squares solution is applied to estimate $E_{\perp}^{\prime}$ from measurements from these altitudes for each profile. This procedure yields $E_{\perp}^{\prime} \approx$ $70 \mathrm{mV} \mathrm{m}^{-1}$ for each of the profiles shown in Fig. 1 .

Using $E_{\perp}^{\prime}$ estimated from E-region ion temperatures, full ion temperature profiles for the main F-region species $\left(\mathrm{O}^{+}\right.$ and $\mathrm{NO}^{+}$) can be calculated from the model Eq. (2). To facilitate comparison with observations, the $\mathrm{NO}^{+}$and $\mathrm{O}^{+}$ temperatures can be related to average ion temperature (what ISR estimates). The average ion temperature is given by a density-weighted average of the individual species temperatures (e.g., Jenkins et al., 1997).

$T_{i \|}=\frac{n_{\mathrm{O}^{+}}}{n_{e}}\left(T_{\mathrm{O}^{+} \|}-T_{\mathrm{NO}^{+} \|}\right)+T_{\mathrm{NO}^{+} \|}$

In this equation it is assumed that $\mathrm{NO}^{+}$and $\mathrm{O}^{+}$are the only ion species present in significant concentrations. Note that this equation implies that $T_{\mathrm{O}^{+} \|} \leq T_{i \|} \leq T_{\mathrm{NO}^{+} \|}$since $\beta_{\|}$is smaller for $\mathrm{O}^{+}$than for $\mathrm{NO}^{+}$(Winkler et al., 1992). Thus, the E-region the average temperature should follow the $\mathrm{NO}^{+}$ temperature, in the region of transition from $\mathrm{NO}^{+}$to $\mathrm{O}^{+}$the average temperature will be between the $\mathrm{NO}^{+}$and $\mathrm{O}^{+}$temperatures, and above the transition region the average temperature will essentially be the $\mathrm{O}^{+}$temperature. The calculations of $\mathrm{NO}^{+}$and $\mathrm{O}^{+}$temperatures are shown alongside the observed average ion temperature profile as dashed lines in panels (b) and (c) of Fig. 1. Basic features of modeled profiles in these cases (and in general) are a single broad maximum around $160 \mathrm{~km}$ and small negative gradient above.

Observed and modeled profiles in Fig. 1 match well below $150 \mathrm{~km}$ and above $275 \mathrm{~km}$, but there is poor agreement in the region of $150-225 \mathrm{~km}$. The model temperature for both species is systematically much higher in this region. Differences between the data and model approach $500-800 \mathrm{~K}$, two to four times larger than the error bars for the measurements. It is, therefore, unlikely that these differences are of a statistical nature. Furthermore, the data-model discrepancies are present throughout the 26 February 2001 case study event. Observed ion temperature profiles (estimated based on assumed ion composition profiles) are inconsistent with the theoretical model of ion frictional heating described by Eq. (2).

It is conceivable that inaccuracies in some model parameters in Eq. (2) could lead to the data-model inconsistency noted above. The energy partitioning factor $\left(\beta_{\|}\right)$for each species will depend on the importance of Coulomb collisions (McCrea et al., 1993). For the profiles presented in Fig. 1 it was found that Coulomb collision rates (calculated from ISR measurements) were relatively small compared to ion-neutral collision rates (calculated from NRLMSIS-00).

Both $\beta_{\|}$and $\left\langle m_{\mathrm{n}}\right\rangle$ are dependent on neutral atmospheric composition (St-Maurice and Schunk, 1977, 1979; Winkler et al., 1992), which is known to vary significantly, especially at high latitudes (e.g., Meier et al., 2005). Figure 2 shows calculations of ion temperature profiles for a set effective electric field of $70 \mathrm{mV} \mathrm{m}^{-1}$ and variable $\mathrm{O} / \mathrm{N}_{2}$ ratios. Panel (a) of Fig. 2 shows $\mathrm{NO}^{+}$temperature, which is used in the evaluation of the effective electric field. In the $130-150 \mathrm{~km}$ region, the $\mathrm{NO}^{+}$parallel temperature is not strongly dependent on neutral atmospheric composition. This implies that an accurate estimation of the effective electric field can be made from the E-region ion temperature measurements, regardless of neutral atmospheric variability. The $\mathrm{O}^{+}$parallel temperature (panel b of Fig. 2) is more strongly affected by neutral composition which controls the types of collisions the $\mathrm{O}^{+}$ 

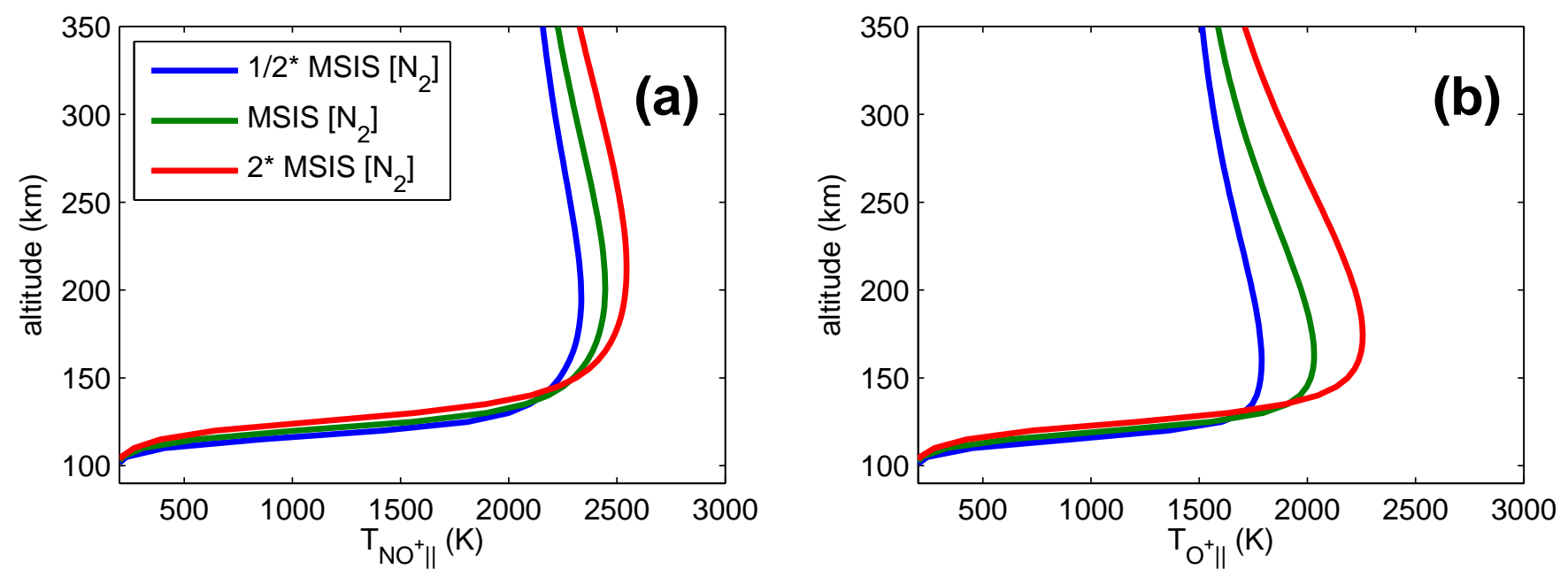

Fig. 2. Effects of varying the $\mathrm{O} / \mathrm{N}_{2}$ ratio on shapes of ion temperature profiles for dominant F-region species.

undergoes $\left(\mathrm{O}^{+}-\mathrm{N}_{2}\right.$ is a polarization collision while $\mathrm{O}^{+}-\mathrm{O}$ is charge exchange). However, these temperature calculations do show that variability in the neutral atmosphere cannot explain the ion temperature inversions observed throughout the 26 February 2001 case study event (and in other data sets as discussed in Sect. 4).

Shears in neutral wind velocity could affect the ion temperature profile shape by making the effective electric field altitude-dependent (as indicated by Eq. 3). This would invalidate previous assumptions used in the model calculations. To investigate possible neutral wind shears, the effective electric field is calculated at different altitudes where the composition is known to a high degree of confidence. For the 26 February 2001 data set ion temperature measurements at $\sim 133 \mathrm{~km}, \sim 145 \mathrm{~km}$ (where ions are assumed to be $\mathrm{NO}^{+}$) and at $\sim 295 \mathrm{~km}$ (where they are assumed to be $\mathrm{O}^{+}$) are used. Table 1 summarizes the results of calculating the effective electric field vs. altitude for the profiles in Fig. 1, panels (b) and (c). These calculations suggest that the effective electric field does not vary enough with altitude to explain the temperature inversions observed. The local minima in the observed temperature profiles at $200 \mathrm{~km}$ would require roughly a 25$30 \mathrm{mV} \mathrm{m}^{-1}$ reduction in the effective electric field at that altitude compared to the effective electric field in the E-region. The modest increase in effective electric field at $295 \mathrm{~km}$ is likely due to the presence of a small amount of $\mathrm{NO}^{+}$which has a larger $\beta_{\|}$, or the increasing influence of Coulomb collisions near the F-region peak which drive the ion distributions toward isotropy by effectively increasing $\beta_{\|}$(McCrea et al., 1993). These calculations do not entirely preclude the presence of a lower effective electric field at $200 \mathrm{~km}$, but do show that enormous wind shears in the $150-200 \mathrm{~km}$ and 200-275 km regions would be required to support such a decrease in $E_{\perp}^{\prime}$. Based on these points, it is assumed in the rest of this analysis that wind shears do not play a dominant
Table 1. Effective electric field vs. altitude for the ion temperature profiles of Fig. 1.

\begin{tabular}{ccc}
\hline altitude & $E_{\perp}^{\prime}$ at 03:23:28 UT & $E_{\perp}^{\prime}$ at 03:28:08 UT \\
\hline $133 \mathrm{~km}$ & $71 \pm 4 \mathrm{mV} \mathrm{m}^{-1}$ & $71 \pm 9 \mathrm{mV} \mathrm{m}^{-1}$ \\
$145 \mathrm{~km}$ & $65 \pm 5 \mathrm{mV} \mathrm{m}^{-1}$ & $70 \pm 8 \mathrm{mV} \mathrm{m}^{-1}$ \\
$295 \mathrm{~km}$ & $87 \pm 7 \mathrm{mV} \mathrm{m}^{-1}$ & $75 \pm 7 \mathrm{mV} \mathrm{m}^{-1}$ \\
\hline
\end{tabular}

role in structuring ion temperature in the $150-250 \mathrm{~km}$ altitude range. There are very few studies of vertical structure in zonal and meridional neutral winds to corroborate this assumption. Rino et al. (1977); Thayer (1998) and St.-Maurice et al. (1999) have presented compelling evidence of vertical structure in the E-region based on ISR measurements and analysis of the ion momentum and energy equations. However, their studies are limited to regions where ion composition can be accurately determined so there is little information about vertical structure in F-region neutral winds.

Having ruled out other sources of discrepancy, it seems plausible that the composition profile assumed in the ISR analysis is a source of data-model discrepancy noted in the previous section. A full fluid-kinetic ionospheric model is used in the next section to directly evaluate the transient response of ionospheric composition to effective electric fields.

\section{Modeled ionosphere at auroral boundaries}

The TRANSCAR model (Blelly et al., 1996b; Lilensten and Blelly, 2002), which solves the full ion transport equations, is used to investigate the effects of transient frictional heating on ion composition. TRANSCAR solves the 13moment transport equations, along geomagnetic field lines (Blelly and Schunk, 1993), for seven different ion species: 

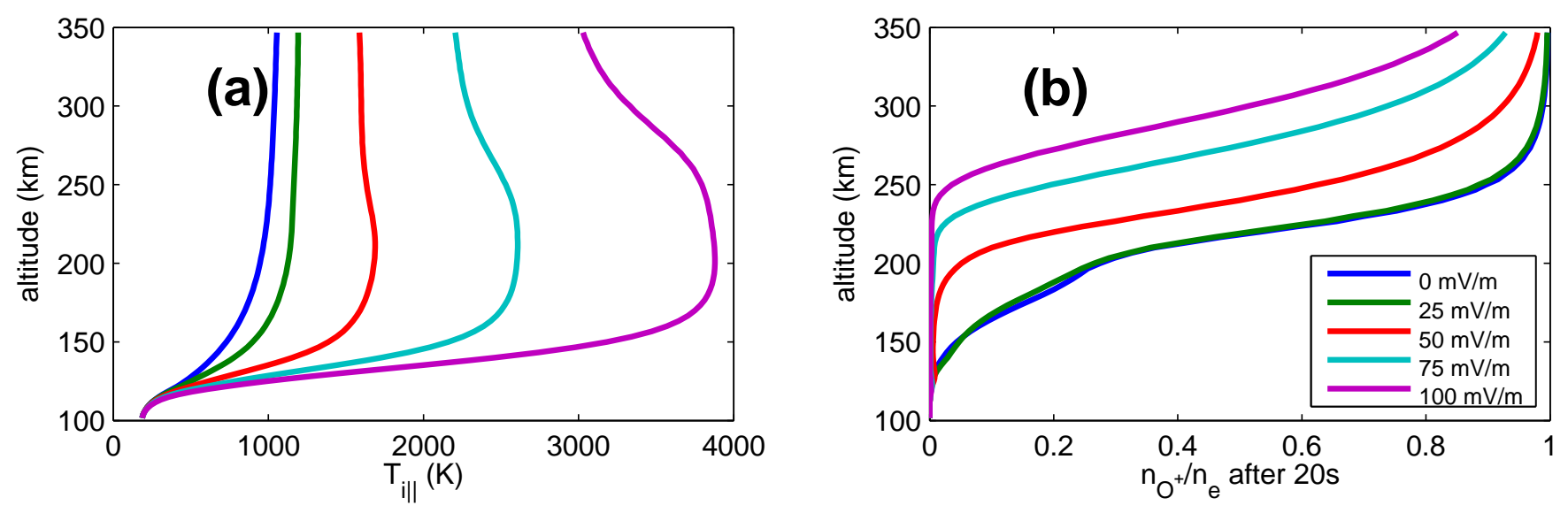

Fig. 3. TRANSCAR simulations of the effects of electric fields of varying intensity on the ionosphere. The legend in panel (b) applies universally to this figure. Panel (a) enhanced parallel ion temperatures. Panel (b) ion composition shown as the fraction of the plasma that is $\mathrm{O}^{+}$.

$\mathrm{O}^{+}, \mathrm{H}^{+}, \mathrm{N}^{+}, \mathrm{N}_{2}^{+}, \mathrm{NO}^{+}, \mathrm{O}_{2}^{+}$, and $\mathrm{e}^{-}$. All temperature dependent chemistry relevant to the E- and F-regions is included in the model (Diloy et al., 1996). In addition, TRANSCAR also includes a kinetic module which solves a simplified Boltzmann equation for suprathermal electrons (Lummerzheim and Lilensten, 1994) and calculates impact ionization, excitation, and electron heating rates. Electric field induced frictional heating processes are included in TRANSCAR through heating terms in the ion energy equations (Diloy et al., 1996). Because TRANSCAR is a full fluidkinetic model of the ionosphere, the simulations in this section represent a more complete treatment of effects of ion frictional heating than was undertaken in the previous section.

TRANSCAR has been been used in past data-model comparisons of ion composition (Lathuillere et al., 1997), but here the model is used to examine the transient response to sudden $(<1 \mathrm{~min})$ disturbances in the effective electric field. Furthermore, these simulations will be used to characterize the behavior of ion composition vs. effective electric field in sudden disturbances. For this study, a series of TRANSCAR simulations is performed, each of which models the ionospheric response at Sondrestrom, Greenland to an electric field of varying strength near the edge of an auroral arc. The electric field is applied to the simulation starting at 03:00 UT ( $\sim$ midnight LT) for $40 \mathrm{~s}$ to model a transient frictional heating event. This type of simulation demonstrates the magnitude of ion composition and density variations on short time scales associated with auroral activity. Lastly, a weak electron flux (total energy flux of $0.5 \mathrm{~mW} \mathrm{~m}^{-2}$ ) is used to model diffuse background precipitation near the arc. These conditions were specifically chosen to match those observed during the 26 February 2001 Sondrestrom ISR experiment.

Figure 3 shows plots of the simulated average ion temperature and composition vs. electric field strength. Figure 3, panel (a) shows the large enhancements in ion temperature that occur from frictional heating. The enhancement of ion temperature above the neutral atmospheric temperature is, to leading order, proportional to $E_{\perp}^{\prime 2}$ (e.g. St.-Maurice et al., 1999). Significant departures of the ion temperature from the quiescent nighttime temperature (the $0 \mathrm{mV} \mathrm{m}^{-1}$ curve in Fig. 3) occur for electric fields $\geq 50 \mathrm{mV} \mathrm{m}^{-1}$. Fields exceeding $75 \mathrm{mV} \mathrm{m}^{-1}$ produce drastic temperature enhancements of $>2$ times the quiescent nighttime temperature. Below $\sim 350 \mathrm{~km} T_{i}$ enhancements reach a steady state in $10 \mathrm{~s}$ or less (basically the ion-neutral collision time) in the simulations. As with the simpler frictional heating model used in the previous section, note the inconsistency in the profile shapes in Fig. 3, panel (a) and observations presented in Fig. 1. These TRANSCAR results are more compelling as they are directly comparable to the observations, since they include the effect of ion composition on average temperature. Moreover, these simulations include secondary effects of Coulomb collisions and ion heat flows on F-region temperatures.

High temperatures persisting for as little as $20 \mathrm{~s}$ convert a large fraction of F-region plasma to a molecular ion plasma. Figure 3, panel (b) shows ionospheric composition (plotted as the ratio of atomic ions to total plasma density) in the E- and F-regions in response to a 20 s electric field disturbance. Electric fields $<37.5 \mathrm{mV} \mathrm{m}^{-1}$ in magnitude produce very minor modifications of the molecular to atomic ion transition altitude (where $n_{\mathrm{O}^{+}} / n_{e}=1 / 2$ ). For an electric field of $50 \mathrm{mV} \mathrm{m}^{-1}$ the transition altitude increases by $\sim 30-40 \mathrm{~km}$. Electric fields stronger than $\sim 50 \mathrm{mV} \mathrm{m}^{-1}$ produce dramatic changes in transition altitude, raising it by as much as $100 \mathrm{~km}$. 

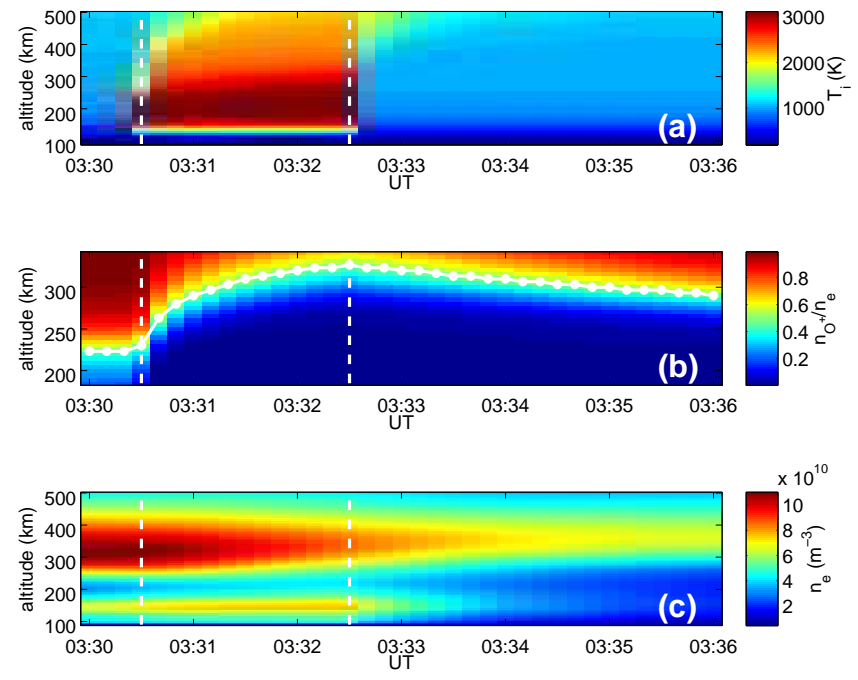

Fig. 4. TRANSCAR simulations of the temporal features of ionospheric response to a $75 \mathrm{mV} \mathrm{m}^{-1}$ effective electric field. The beginning and end times of the electric field disturbance are marked by dashed lines in all panels. Panel (a) ion temperature vs. altitude and time. Panel (b) ion composition shown as the fraction of the plasma that is $\mathrm{O}^{+}$. The altitude at which the plasma is $50 \% \mathrm{O}^{+}$is marked by a solid line. Panel (c) plasma density vs. altitude and time.

The simulated ionospheric response to effective electric fields shows interesting and important temporal features. Figure 4 shows simulation results of applying an effective electric field disturbance $\left(75 \mathrm{mV} \mathrm{m}^{-1}\right.$ magnitude) to the nighttime auroral ionosphere for a period of two minutes. The time resolution of the simulation output is $10 \mathrm{~s}$, so transients in the response can be fully resolved. Panel (a) of Fig. 4 shows the ion temperature responds very quickly to an electric field disturbance. Below $400 \mathrm{~km}$, the temperature reaches equilibrium (between frictional heat input and heat exchange loss to neutrals) in $\sim 30 \mathrm{~s}$. This suggests that, for purposes of comparison with ISR data having $30 \mathrm{~s}$ integration, ion temperature can be assumed to be in steady-state equilibrium. In contrast, the ion composition varies continuously during the $2 \mathrm{~min}$ disturbance. After $30 \mathrm{~s}$ the molecular to atomic ion transition altitude has risen from its nighttime value of $\sim 215 \mathrm{~km}$ to $\sim 275 \mathrm{~km}$. After $2 \mathrm{~min}$ the crossover altitude is $\sim 315 \mathrm{~km}$; the F-region peak is composed of $50 \%$ $\mathrm{NO}^{+}$at this time. Another important feature of the composition response is that it remains disturbed, even after the cessation of the electric field disturbance. The atomic to molecular ion transition altitude slowly lowers after the disturbance due to the faster recombination of the molecular ions which were created near the F-region peak.

Figure 4, panel (c) shows a plot of plasma density vs. time during the simulation. The enhancement in $\mathrm{NO}^{+}$results in more recombination and plasma depletions, which will be revisited in the discussion in Sect. 6.

\section{Effects of erroneous ion composition on ISR temper- ature profiles}

As noted in the introduction, the composition variability simulated in Fig. 3 will have important implications for analysis of ISR spectra. When fitting the IS spectrum, there is no way to correctly specify the type of highly variable ion composition simulated in Fig. 4. It is, therefore, worthwhile to consider what observable features will occur in temperature profiles when the spectra are processed with an incorrect, static composition. To this end, a simulated ion temperature profile is reprocessed with the model of ion composition used at the Sondrestrom ISR facility to illustrate the ion temperature that would be inferred from the standard analysis. Figure 5 shows the results of such a calculation. In panel (a), ion composition profiles are shown for the $50 \mathrm{mV} \mathrm{m}^{-1}$ simulation and from the standard Sondrestrom model. Panel (b) shows the simulated ion temperature for an electric field of $50 \mathrm{mV} \mathrm{m}^{-1}$ and the ion temperature that would be estimated by the Sondrestrom analysis (using its standard, static composition model) when the composition is actually that shown by the dashed line in panel (a). The "observed" Sondrestrom temperature profile deviates greatly from theoretical models of ion frictional heating, and has the inversion characteristics noted in the data presented in Fig. 1.

Figure 5 highlights the fact that errors induced by inaccurate composition models should appear as systematic biases anywhere high temperatures (and effective electric fields) are present. It can be seen by comparing Fig. 3, panel (b) with Fig. 5, panel (a), that the altitude extent of fitter composition inaccuracy ranges from $\sim 175-310 \mathrm{~km}$. As the effective electric field increases, the altitude region in which the true composition deviates from the model used by Sondrestrom becomes larger. In general, the increased mass in the $175-310 \mathrm{~km}$ region will present itself as underestimated temperatures in this region, producing an apparent temperature inversion (Fig. 5, panel b). The result, from a data interpretation standpoint, will be ion temperature profiles that have high temperatures below $175 \mathrm{~km}$, low temperatures from $175-310 \mathrm{~km}$, and high temperature above $310 \mathrm{~km}$. This type of temperature profile should be easily identifiable in fitted data as demonstrated in Fig. 5, panel (b). The electron temperature may display similar characteristics since it is also affected by assumptions of ion composition (Waldteufel, 1971). It is a more difficult matter to predict the exact shape of the electron temperature profile, however, since it is affected by plasma instabilities (Schlegel and St.-Maurice, 1981) and energy transfer from precipitating electrons (e.g. Lynch et al., 2007; Zettergren et al., 2007).

A survey of Sondrestrom data near the last solar maximum confirms that temperature inversions are systematically observed during ion heating events. Figure 6 shows a twodimensional histogram of ion temperature vs. altitude which includes profiles having $T_{i}>2000 \mathrm{~K}$ during the 1 January 1998-31 December 2001 period. This figure represents a 

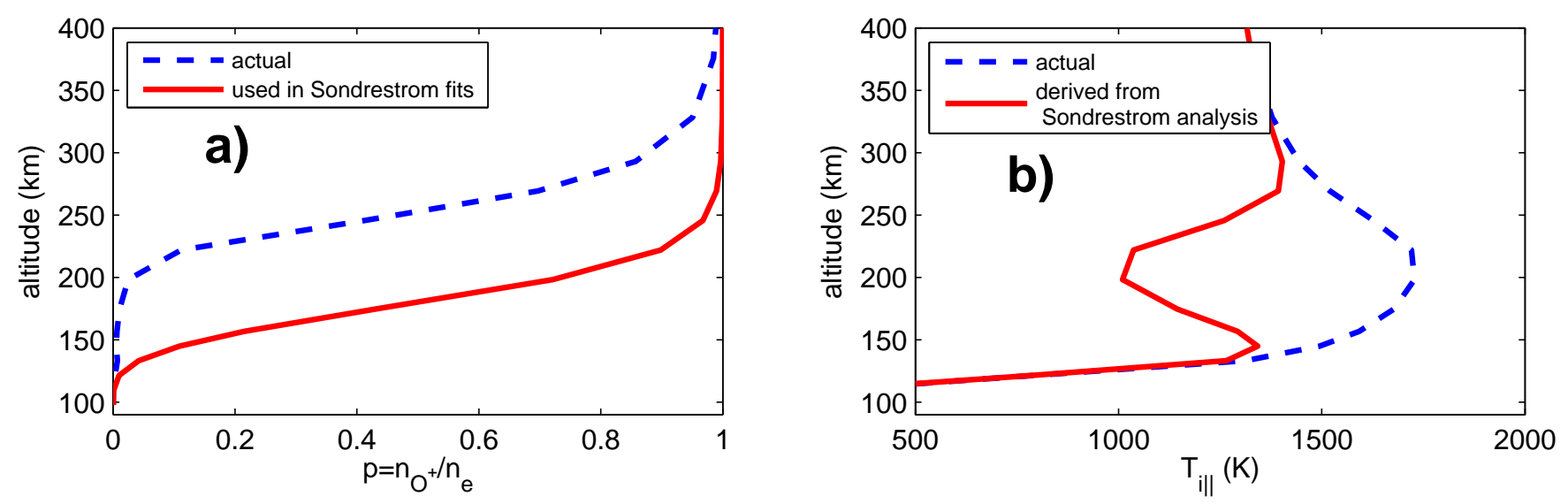

Fig. 5. Illustration of the effects of fitting IS spectra with an incorrect composition model. Panel (a) actual (modeled) composition for $E_{\perp}=50 \mathrm{mV} \mathrm{m}^{-1}$ and the composition used in fitting Sondrestrom data. Panel (b) modeled ion temperature for $E_{\perp}=50 \mathrm{mV} \mathrm{m}^{-1}$ and temperature derived using the red line composition profile from panel (a).

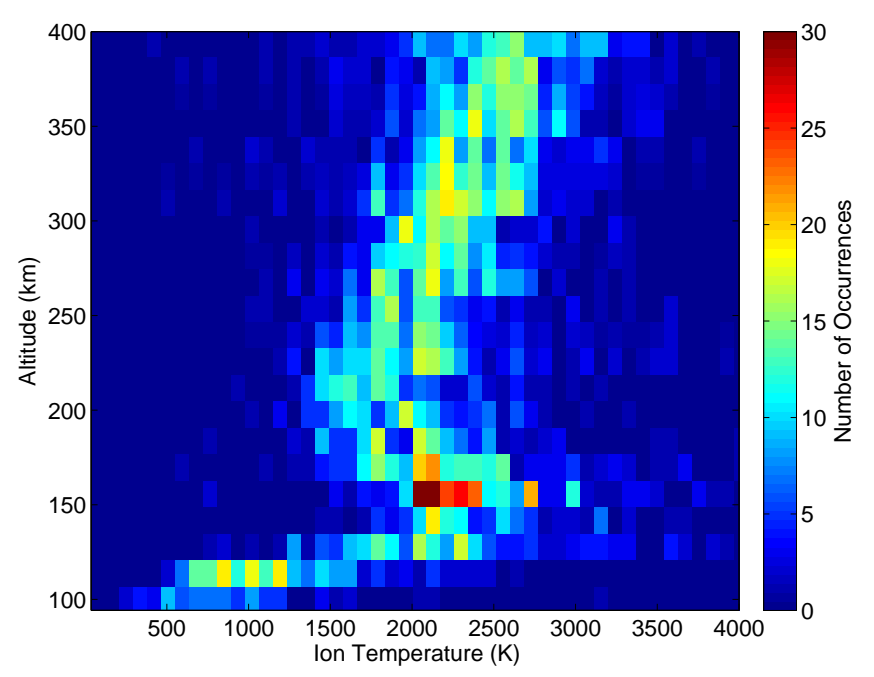

Fig. 6. A two-dimensional histogram of ion temperature vs. altitude. Profiles like those shown in Fig. 1 show up statistically in the histogram.

total of 506 ion temperature profiles (4045 individual point measurements). To construct this histogram, temperature data were placed into bins of width $85 \mathrm{~K}$ and altitude bins of width $15 \mathrm{~km}$. A trend of high temperature profiles having inversions similar to that presented in Fig. 1, panels (b) and (c) is clear in the data summarized in Fig. 6. The inversion region seen in the statistical results matches the location and size of the variable composition regions modeled with TRANSCAR.

\section{Resolving the data-model inconsistencies}

Simulations in Fig. 3 corroborate previous work (see introduction) showing that ion composition can vary greatly in response to strong perpendicular electric fields. These variations are not taken into account in standard ISR analysis and will, therefore, result in incorrect ion temperatures deduced from the IS spectra (Oyama et al., 2004). This section quantitatively examines this source of error as a possible cause of the apparent temperature inversions and the data-model discrepancy demonstrated in Fig. 1.

As stated previously, ion and electron temperatures are obtained from Sondrestrom IS spectra only by assuming an ion composition profile. Waldteufel (1971) developed a technique that allows ion temperatures obtained from fitting with a particular composition profile to be converted to temperature profiles under different assumptions of ion composition. This method affords efficient reprocessing of temperature profiles for easy analysis of the effects of composition on the spectral fitting process. The method is inexact, but is accurate to within $\sim 5 \%$ (Oliver, 1979).

To attempt to resolve data-model discrepancies, ion temperature profiles are reprocessed with a model ion composition representative of estimated effective electric fields $\left(\sim 70-75 \mathrm{mV} \mathrm{m}^{-1}\right)$ for the 26 February 2001 case study. Composition profiles obtained from TRANSCAR are adopted, as they are deemed more physically realistic than the standard ion composition profile used by the Sondrestrom fitter. I.e. TRANSCAR computes a fully self-consistent set of plasma parameters (Blelly et al., 1996a) (including their spatial and temporal variability) resulting from frictional heating, while standard ISR fitter analysis imposes no such constraints.

Figure 7, panels (b) and (c) show ion temperature profiles from Fig. 1, panels (b) and (c), reprocessed with an ion composition profile shown in panel (a). This ion composition profile is from the TRANSCAR simulation using $E_{\perp}^{\prime}=75 \mathrm{mV} \mathrm{m}^{-1}$ after $30 \mathrm{~s}$ exposure to electric field. This composition profile likely represents a lower bound in the deviation from the one used by the Sondrestrom fitter, since 

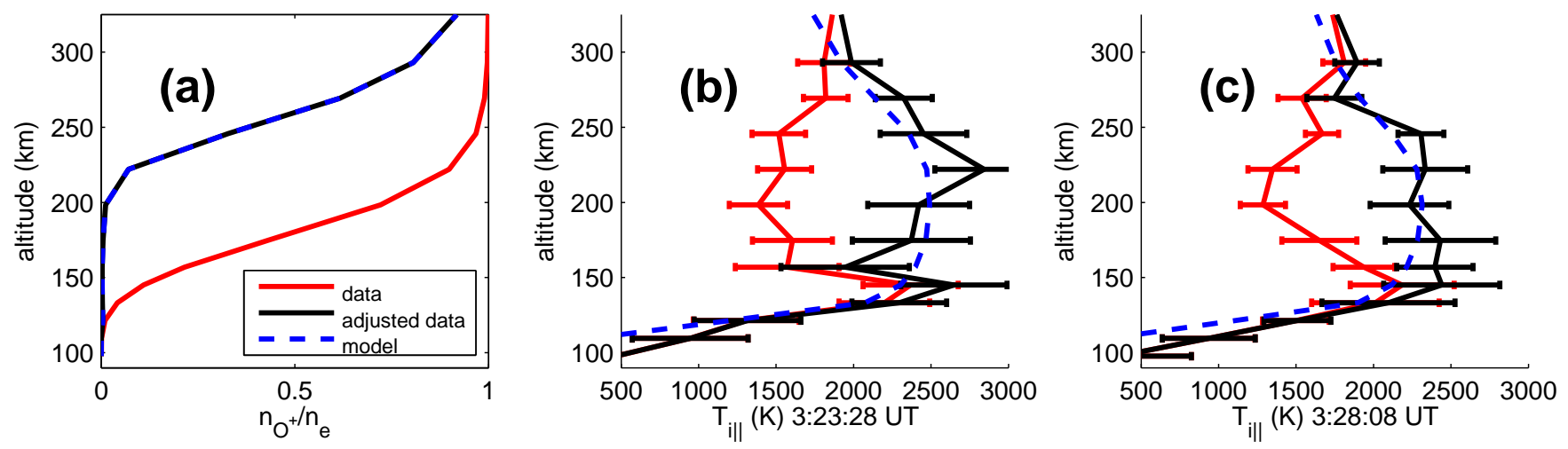

Fig. 7. ISR ion temperature profiles reprocessed with TRANSCAR ion composition profile. Panel (a) Ion composition profiles from standard Sondrestrom analysis and TRANSCAR model. Panels (b) and (c) Temperatures from Sondrestrom analysis and from reprocessing of data with TRANSCAR composition profile.

longer exposure to electric fields would produce a higher upward shift in the composition profile (Fig. 4, panel b). Visual inspection reveals that the data and model are in much closer agreement if a physically reasonable ion composition profile (provided by TRANSCAR in this case) is used in the temperature determination. Whereas, previously, temperature model calculations were well outside measurement error bars (Fig. 1), now the model falls within almost all measurement error bars for both profiles shown. Quantitative calculations further reveal that there is less discrepancy (measured as mean-square difference) between data and model by adopting the TRANSCAR ion composition profile.

In general, it is found that a judicious choice of ion composition profile (consistent with TRANSCAR simulations) provides better data-model agreement for the majority of profiles observed during the 26 February 2001 case study event. Cursory analysis of other data sets with measurements during strong frictional heating reveal similarly better agreement. If it is assumed that the theory of frictional heating and the empirical models used in calculations are somewhat accurate, then the ion composition and temperature profiles in the reprocessed data better explain the observed IS spectra than the profiles derived from the standard analysis.

As a final note, specifying ion composition from a model such as TRANSCAR is still problematic for analyzing ISR data, even though it encapsulates the physics of frictional heating. As suggested by the modeling in Fig. 4, the time history of the convecting plasma must be known to properly specify ion composition. This is not possible for a fixed-position radar, so it has been assumed in the analysis of Fig. 7 that plasma has been exposed to the frictional heating for only a short time $(\sim 30 \mathrm{~s})$ in order to model the composition with TRANSCAR. Like the standard analysis procedure, such an assumption is, of course, completely ad hoc and cannot form the basis for a systematic analysis strategy. It seems that a better method for analyzing the ISR data would be to model the ion temperature and estimate the ion composition. The ion temperature below $\sim 350 \mathrm{~km}$ reaches a steady-state very quickly after application of an electric field, so it is much easier to predict (assuming an accurate model is available) based on instantaneous estimates of the effective electric field.

Despite the improved data-model agreement obtained by adjust the ion composition profile, there are still significant differences in the temperature profiles (e.g. the 03:23:28 profile at $157 \mathrm{~km})$. The fact that this difference exists in the Eregion suggests that it is not due to incorrectly specifying the exposure time of the plasma to the electric field, since time constants are short in that region. In light of this, it seems plausible that this continued difference is due to neutral wind shears that have been "assumed away" in the analysis of the effective electric field (see Sect. 2).

\section{Plasma depletions associated with composition variability}

Electric field disturbances create significant depletions in Fregion plasma density through modification of ion composition. Conversion of a significant fraction of the ionosphere to molecular ions reduces the effective ion lifetime (molecular ions recombine faster). Figure 4, panel (c) shows a simulation of F-region plasma density depletion due to enhanced molecular ion content in the plasma. The effective electric field in this simulation is $75 \mathrm{mV} \mathrm{m}^{-1}$. The depletion begins with the electric field disturbance and actually continues even after the disturbance. The sudden heating quickly converts a large fraction of the plasma in the F-region to $\mathrm{NO}^{+}$during the 2 min disturbance. This $\mathrm{NO}^{+}$then continues to recombine over the minutes following the disturbance. This process yields $\sim 50 \%$ depletion in plasma at the F-region peak, and even larger fractional depletions at lower F-region altitudes. These depletions persist indefinitely absent some significant source of ionization. 

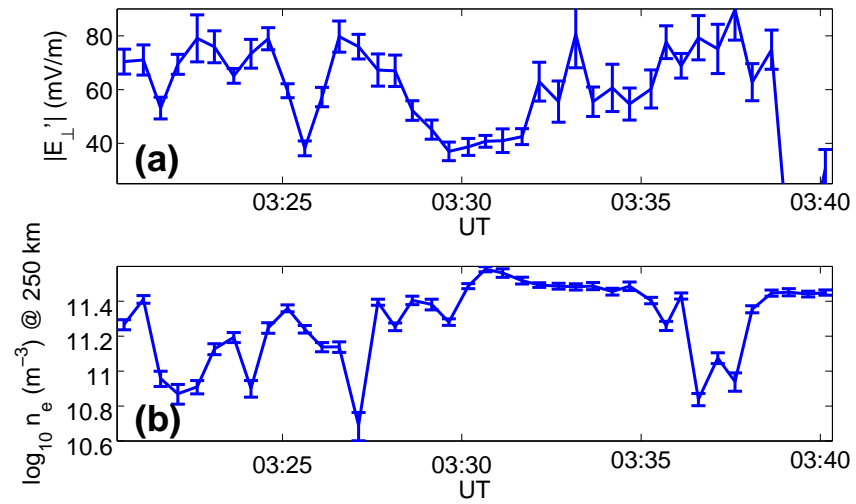

Fig. 8. Plasma depletions associated with variable ion composition. Panel (a) Effective electric field estimated from E-region ion temperature. Panel (b) Plasma density in lower F-region.

Observations during the 26 February 2001 case study confirm the presence of plasma depletions associated with inferred enhancements in molecular ion densities. Figure 8, panel (a) shows a plot of effective electric field estimated from ion temperature in the E-region during the event. Figure 8, panel (b) shows fitted electron density (which is not strongly affected by ion composition (Waldteufel, 1971; Jenkins et al., 1997)) in the lower F-region during the same times. As seen in these panels, large depletions in plasma density are associated with spikes in the effective electric field. Ion temperature profiles during these times show artificial inversions indicative of variable composition. This is consistent with the hypothesis that both the observed ion temperature profile shapes and the depletions are associated with large enhancements in $\mathrm{NO}^{+}$in the plasma. Depletions also speak to our earlier assumption that neutral wind shears are a minor factor contributing ion temperature profile shape since there seems to be no clear reason for depletions to be systematically associated with large wind shears.

Figures 3, panel (c) and 8, panel (b) suggest that ion composition plays a significant role in structuring plasma density in the auroral zone and polar cap (Grebowsky et al., 1983; Rodger et al., 1992). In general, plasma depletions should be associated with auroral arc morphology according to the type of electric field patterns of the arc (Marklund, 1984). In addition, the model results presented in Fig. 4 indicate that the depletions caused by a spatially confined electric field disturbance may become entrained in the global convection pattern and move around. Thus, even a spatially confined auroral arc feature can affect plasma distribution over a wide range of latitudes and local times.

The formation of plasma depletions in association with auroral arcs is usually attributed to electrodynamic processes based on the short (1-5 min) time scales of formation of the depletions (Doe et al., 1993, 1994; Aikio et al., 2004; Streltsov and Lotko, 2008). One such depletion mechanism results from the need of the ionosphere to maintain current continuity through adjacent upward and downward current regions. Typically, upward current regions will have large plasma densities caused by impact ionization from the precipitating electrons comprising the current. In contrast, the adjacent downward current is carried by thermal ionospheric electrons (moving upward). The up-down field-aligned current pair is closed by a Pederson current (carried by ions) flowing from downward to upward current channels. The exodus of ions (through the Pederson current) and electrons (moving upward to carry the downward field-aligned current) results in a net plasma loss in the downward current channel. Observations have shown that, in the E- and F-region ionospheres, this process can create depletions (Marklund et al., 2001). Current continuity is maintained by either broadening of the downward current channel (Cran-McGreehin et al., 2007) or by accessing charge carriers from the F-region, thus depleting the lower F-region, as well (Doe et al., 1995; Karlsson et al., 2005).

Another mechanism for plasma depletions involves the reflection and trapping of small-scale Alfvén waves in large scale current system. In a large scale downward current, conditions are favorable for the ionospheric feedback instability (Lysak and Song, 2002) which reflects small-scale Alfvén waves back toward the magnetosphere where they can then be trapped in the ionospheric Alfvén resonator (e.g. Streltsov and Lotko, 2004). Modeling of this process has shown that the intensity of the trapped waves is sufficient to produce a ponderomotive force capable of evacuating the lower F-region of the ionosphere (Streltsov and Lotko, 2008). Given that small-scale Alfvén waves are a common feature of the high-latitude magnetosphere (Stasiewicz et al., 2000), it seems likely that this mechanism contributes significantly to observed plasma depletions.

TRANSCAR modeling results in this work (Fig. 3) indicate that F-region depletions of $\sim 40-50 \%$ can be caused in a matter of minutes due to electric field-induced heating and enhanced recombination. It is well-established that electric fields are typically strong in downward current regions (e.g. Johnson et al., 1998), so it seems likely that enhanced recombination processes act in concert with the current closure and Alfvén wave mechanisms to produce plasma depletions. The modeled magnitude and time scale for depletion due to enhanced recombination (Fig. 4) is comparable to that of ionospheric evacuation in downward current region due to electrodynamic processes (Doe et al., 1993, 1994, 1995; Streltsov and Lotko, 2008). Undoubtedly, all of these mechanisms (composition, current closure, ionospheric feedback instabilities) can be present near auroral arcs, but their relative contributions to producing the plasma depletions is unclear. A combined modeling of all of these physical processes will likely be needed to fully address this issue.

F-region plasma depletions also have important consequences for magnetosphere ionosphere mass coupling. There is a significant body of evidence suggesting that the F-region and topside ionospheric densities modulate the intensity of 
heavy ion outflows to the magnetosphere (e.g. Ogawa et al., 2008). If this is indeed the case, then depletion processes limit plasma supply to the magnetosphere by reducing the reservoir of F-region plasma available for extraction (Semeter et al., 2003; Lotko, 2007). Furthermore, the types of arcrelated molecular ion enhancements simulated and observed in this work are possible sources for molecular ions that are observed in the magnetosphere (Yau et al., 1993; Peterson et al., 1994; Wilson and Craven, 1999). Closer study of these molecular ion enhancements may help shed some light on ion energization processes since molecular outflows are more closely correlated with geomagnetic activity than is $\mathrm{O}^{+}(\mathrm{Pe}-$ terson et al., 1994; Lennartsson et al., 2000).

\section{Conclusions}

Modeling and Sondrestrom ISR evidence of F-region ion composition variability on time scales of less than one minute have been presented in this work. In this work composition variability is inferred through a novel synthesis of apparent ion temperature inversion measurements and careful data-model comparisons. Results indicate that alterations in composition and density can occur in less than $20 \mathrm{~s}$, but have lasting effects as they persist in the absence of significant ion production from auroral sources or photoionization. Disturbed plasma may move to other latitudes and local times, which makes it difficult to determine whether any observed composition changes were caused by electric fields, changes in the neutral atmosphere, or some other driver. Statistical analysis confirms that apparent temperature inversions (composition variability) are systematically observed in concurrence with frictional heating.

Our analysis has included a partial accounting for the effects of neutral winds on heating and composition, through estimation of the effective electric field. As discussed in Sect. 2, analysis of ion energy balance to infer ion composition must include the effects of neutral winds on the effective electric field. This precludes the use of direct measurements of plasma drift (such as the 3-position experiments) for analyzing ion energy balance. However comparison of effective electric fields and electric fields from drift measurements is likely to provide useful information on neutral winds in future work. A remaining issue is the possible existence of large vertical shears in neutral winds, which could also produce structure in ion temperature profiles by making the effective electric field altitude-dependent. Such a wind shear would have an effect similar to variable composition on ion temperature profiles calculated through standard ISR techniques. Some evidence of large neutral wind shears exists (Thayer, 1998; St.-Maurice et al., 1999) and was presented in Sect. 5, but more research is needed to determine the possible extent of these shears in the F-region.

Intense electric fields can produce significant plasma depletions through modification of temperature-dependent chemistry. The data and simulations presented in this paper, in particular, indicate that these depletions can form on time scales similar to depletions caused by electrodynamic processes. As such, it is extrememly difficult to attribute depletions to a single physical process. In fact, it is likely that some combination of this processes is at play in producing auroral plasma depletions. Results and discussion in this paper also indicate that auroral downward current regions could be possible sources for molecular ions which have been observed exiting the ionosphere during storm times (Lennartsson et al., 2000).

As discussed by previous authors (e.g. Lathuillère and Kofman, 2006), accounting for aurorally-induced ion composition in ISR analysis poses a difficult problem. For studying dynamic situations there is not sufficient SNR to directly fit IS spectra for both ion composition and temperatures. Thus, either the composition must be specified (or modeled) to the fitter or the ion temperature must be specified (or modeled). This work suggests that the method of modeling temperature is preferable since it is more directly related to the instantaneous effective electric field, while the composition exhibits significant transients. Spatial domain evidence of variable composition in ion temperature profiles (Fig. 6) presents an opportunity to develop a means to analyze existing databases of ISR measurements. The combined data-model analysis strategy presented herein provides the groundwork for the future development of a method to estimate composition from single beam position ISR experiments.

Acknowledgements. The authors would like to acknowledge Mary McCready for data preparation, and the Sondrestrom site crew for campaign support. MZ would like to thank ISSI in Bern, Switzerland for supporting the development of some of the ideas in this work through their hosted research meetings. The authors would also like to thank Bill Peterson and J.-P. St.-Maurice for useful advice regarding this research.

Topical Editor K. Kauristie thanks two anonymous referees for their help in evaluating this paper.

\section{References}

Aikio, A. T., Mursula, K., Buchert, S., Forme, F., Amm, O., Marklund, G., Dunlop, M., Fontaine, D., Vaivads, A., and Fazakerley, A.: Temporal evolution of two auroral arcs as measured by the Cluster satellite and coordinated ground-based instruments, Ann. Geophys., 22, 4089-4101, 2004,

http://www.ann-geophys.net/22/4089/2004/.

Aruliah, A. L., Griffin, E. M., McWhirter, I., Aylward, A. D., Ford, E. A. K., Charalambous, A., Kosch, M. J., Davis, C. J., and Howells, V. S. C.: First tristatic studies of meso-scale ion-neutral dynamics and energetics in the high-latitude upper atmosphere using collocated FPIs and EISCAT radar, Geophys. Res. Lett., 31, 3802, doi:10.1029/2003GL018469, 2004.

Banks, P.: Collision frequencies and energy transfer. Ions, Planet. Space Sci., 14, 1105, doi:10.1016/0032-0633(66)90025-0, 1966. 
Banks, P. M. and Kockarts, G.: Aeronomy, vol. B, Academic Press, 1973.

Blelly, P. L. and Schunk, R. W.: A comparative study of the timedependent standard 8-, 13- and 16-moment transport formulations of the polar wind, Ann. Geophys., 11, 443-469, 1993.

Blelly, P.-L., Lilensten, J., Robineau, A., Fontanari, J., and Alcaydé, D.: Calibration of a numerical ionospheric model with EISCAT observations, Ann. Geophys., 14, 1375-1390, 1996a.

Blelly, P.-L., Robineau, A., Lilensten, J., and Lummerzheim, D.: 8-moment fluid models of the terrestrial high-latitude ionosphere between 100 and 3000 km, in: Solar Terrestrial Energy Program Ionospheric Model Handbook, edited by: Schunk, R. W., pp. 5372, 1996b.

Buonsanto, M. J., Sipler, D. P., Davenport, G. B., and Holt, J. M.: Estimation of the $\mathrm{O}^{+}, \mathrm{O}$ collision frequency from coincident radar and Fabry-Perot observations at Millstone Hill, J. Geophys. Res., 102, 17267-17274, doi:10.1029/97JA01300, 1997.

Burnside, R. G., Tepley, C. A., and Wickwar, V. B.: The O(+)O collision cross-section - Can it be inferred from aeronomical measurements?, Ann. Geophys., 5, 343-349, 1987.

Cabrit, B. and Kofman, W.: Ionospheric composition measurement by EISCAT using a global fit procedure, Ann. Geophys., 14, 1496-1505, 1996,

http://www.ann-geophys.net/14/1496/1996/.

Cran-McGreehin, A. P., Wright, A. N., and Hood, A. W.: Ionospheric depletion in auroral downward currents, J. Geophys. Res. (Space Physics), 112, 10309, doi:10.1029/2007JA012350, 2007.

de La Beaujardiere, O., Vondrak, R., and Baron, M.: Radar observations of electric fields and currents associated with auroral arcs, J. Geophys. Res., 82, 5051-5062, doi:10.1029/JA082i032p05051, 1977.

Diloy, P.-Y., Robineau, A., Lilensten, J., Blelly, P.-L., and Fontanari, J.: A numerical model of the ionosphere, including the E-region above EISCAT, Ann. Geophys., 14, 191-200, 1996, http://www.ann-geophys.net/14/191/1996/.

Doe, R. A., Mendillo, M., Vickrey, J. F., Zanetti, L. J., and Eastes, R. W.: Observations of nightside auroral cavities, J. Geophys. Res., 98, 293-310, doi:10.1029/92JA02004, 1993.

Doe, R. A., Mendillo, M., Vickrey, J. F., Ruohoniemi, J. M., and Greenwald, R. A.: Coordinated convection measurements in the vicinity of auroral cavities, Radio Sci., 29, 293-309, doi: 10.1029/93RS02129, 1994.

Doe, R. A., Vickrey, J. F., and Mendillo, M.: Electrodynamic model for the formation of auroral ionospheric cavities, J. Geophys. Res., 100, 9683-9696, doi:10.1029/95JA00001, 1995.

Eastes, R. W., Killeen, T. L., Wu, Q., Winningham, J. D., Hoegy, W. R., Wharton, L. E., and Carignan, G. R.: An experimental investigation of thermospheric structure near an auroral arc, J. Geophys. Res., 97, 10539, doi:10.1029/92JA00168, 1992.

Evans, D. S., Maynard, N. C., Troim, J., Jacobsen, T., and Egeland, A.: Auroral vector electric field and particle comparisons. II - Electrodynamics of an arc, J. Geophys. Res., 82, 2235-2249, 1977.

Evans, J.: Theory and practice of ionosphere study by Thomson scatter radar, Proc. IEEE, 57, 496-530, 1969.

Gaimard, P., Lathuillere, C., and Hubert, D.: Non-Maxwellian studies in the auroral $\mathrm{F}$ region: a new analysis of incoherent scatter spectra., J. Atmos. Terr. Phys., 58, 415-433, 1996.

Grebowsky, J. M., Taylor, H. A., and Lindsay, J. M.: Location and source of ionospheric high latitude troughs, Planet. Space Sci., 31, 99-105, doi:10.1016/0032-0633(83)90034-X, 1983.

Haggstrom, I. and Collis, P. N.: Ion composition changes during F-region density depletions in the presence of electric fields at auroral latitudes, J. Atmos. Terr. Phys., 52, 519-529, 1990.

Hubert, D. and Lathuillere, C.: Incoherent scattering of radar waves in the auroral ionosphere in the presence of high electric fields, and measurement problems with the EISCAT facility, J. Geophys. Res., 94, 3653-3662, doi:10.1029/JA094iA04p03653, 1989.

Hubert, D., Leblanc, F., and Gaimard, P.: Current state-of-the-art for the measurement of non-Maxwellian plasma parameters with the EISCAT UHF Facility, Ann. Geophys., 14, 1506-1512, 1996, http://www.ann-geophys.net/14/1506/1996/.

Jenkins, B., Moffett, R. J., Davies, J. A., and Lester, M.: Nightside ion frictional heating: atomic and molecular ion temperature anisotropy and ion composition changes, J. Atmos. Solar-Terr. Phys., 59, 1329-1341, 1997.

Johnson, M. L., Murphree, J. S., Marklund, G. T., and Karlsson, T.: Progress on relating optical auroral forms and electric field patterns, J. Geophys. Res., 103, 4271-4284, doi:10.1029/ 97JA00854, 1998.

Karlsson, T., Marklund, G., Brenning, N., and Axnas, I.: On Enhanced Aurora and Low-Altitude Parallel Electric Fields, Physica Scripta, 72, 419-422, doi:10.1238/Physica.Regular. 072a00419, 2005

Kelly, J. D. and Wickwar, V. B.: Radar measurements of highlatitude ion composition between 140 and $300 \mathrm{~km}$ altitude, J. Geophys. Res., 86, 7617-7626, 1981.

Lathuillere, C.: Ion composition response to auroral energy inputs in the lower F-region, Ann. Geophys., 5, 449-454, 1987.

Lathuillère, C. and Kofman, W.: A short review on the F1-region ion composition in the auroral and polar ionosphere, Adv. Space Res., 37, 913-918, doi:10.1016/j.asr.2005.12.014, 2006.

Lathuillere, C., Lejeune, G., and Kofman, W.: Direct measurements of ion composition with EISCAT in the high-latitude F1 region, Radio Sci., 18, 887-893, 1983.

Lathuillere, C., Kofman, W., Hubert, D., and La Hoz, C.: Evidence of anisotropic temperatures of molecular ions in the auroral ionosphere, Geophys. Res. Lett., 18, 163-166, 1991.

Lathuillere, C., Blelly, P., Lilensten, J., and Gaimard, P.: Storm effects on the ion composition, Adv. Space Res., 20, 1699-1708, doi:10.1016/S0273-1177(97)00575-9, 1997.

Lennartsson, O. W., Collin, H. L., Ghielmetti, A. G., and Peterson, W. K.: A statistical comparison of the outflow of $\mathrm{N}_{2}^{+}, \mathrm{NO}^{+}$ and $\mathrm{O}_{2}^{+}$molecular ions with that of atomic $\mathrm{O}^{+}$ions using Polar/TIMAS observations, J. Atmos. Solar-Terr. Phys., 62, 477483, doi:10.1016/S1364-6826(00)00019-5, 2000.

Lilensten, J. and Blelly, P.-L.: The TEC and F2 parameters are tracers of the ionosphere and thermosphere, J. Atmos. Solar Terr. Phys., 64, 775-793, 2002.

Litvin, A., Kofman, W., and Cabrit, B.: Ion composition measurements and modelling at altitudes from 140 to $350 \mathrm{~km}$ using EISCAT measurements, Ann. Geophys., 16, 1159-1168, 1998, http://www.ann-geophys.net/16/1159/1998/.

Lotko, W.: The magnetosphere ionosphere system from the perspective of plasma circulation: A tutorial, J. Atmos. Terr. Phys., 69, 191-211, doi:10.1016/j.jastp.2006.08.011, 2007.

Lummerzheim, D. and Lilensten, J.: Electron transport and energy 
degradation in the ionosphere: evaluation of the numerical solution, comparison with laboratory experiments and auroral observations, Ann. Geophys., 12, 1039-1051, 1994, http://www.ann-geophys.net/12/1039/1994/.

Lynch, K. A., Semeter, J. L., Zettergren, M., Kintner, P., Arnoldy, R., Klatt, E., LaBelle, J., Michell, R. G., MacDonald, E. A., and Samara, M.: Auroral ion outflow: low altitude energization, Ann. Geophys., 25, 1967-1977, 2007, http://www.ann-geophys.net/25/1967/2007/.

Lyons, L. R.: Formation of auroral arcs via magnetosphereionosphere coupling., Rev. Geophys., 30, 93-112, 1992.

Lysak, R. L. and Song, Y.: Energetics of the ionospheric feedback interaction, J. Geophys. Res. (Space Physics), 107, 1160, doi: 10.1029/2001JA000308, 2002.

Marklund, G.: Auroral arc classification scheme based on the observed arc-associated electric field pattern, Planet. Space Sci., 32, 193-211, doi:10.1016/0032-0633(84)90154-5, 1984.

Marklund, G. T., Ivchenko, N., Karlsson, T., Fazakerley, A., Dunlop, M., Lindqvist, P., Buchert, S., Owen, C., Taylor, M., Vaivalds, A., Carter, P., André, M., and Balogh, A.: Temporal evolution of the electric field accelerating electrons away from the auroral ionosphere, Nature, 414, 724-727, 2001.

McCrea, I. W., Lester, M., Robinson, T. R., St.-Maurice, J.-P., Wade, N. M., and Jones, T. B.: Derivation of the ion temperature partition coefficient beta-parallel from the study of ion frictional heating events, J. Geophys. Res., 98, 15701-15715, 1993.

McFarland, M., Albritton, D. L., Fehsenfeld, F. C., Ferguson, E. E., and Schmeltekopf, A. L.: Flow-drift technique for ion mobility and ion-molecule reaction rate constant measurements. II. Positive ion reactions of $\mathrm{N}^{+}, \mathrm{O}^{+}$, and $\mathrm{H}_{2}^{+}$with $\mathrm{O}_{2}$ and $\mathrm{O}^{+}$with $\mathrm{N}_{2}$ from thermal to $\sim 2 \mathrm{eV}$, J. Chem. Phys., 59, 6620-6628, 1973.

Meier, R. R., Crowley, G., Strickland, D. J., Christensen, A. B., Paxton, L. J., Morrison, D., and Hackert, C. L.: First look at the 20 November 2003 superstorm with TIMED/GUVI: Comparisons with a thermospheric global circulation model, J. Geophys. Res. (Space Physics), 110, 9, doi:10.1029/2004JA010990, 2005.

Moore, T. E. and Horwitz, J. L.: Stellar ablation of planetary atmospheres, Rev. Geophys., 45, G3002, doi:10.1029/ 2005RG000194, 2007.

Ogawa, Y., Seki, K., Hirahara, M., Asamura, K., Sakanoi, T., Buchert, S. C., Ebihara, Y., Obuchi, Y., Yamazaki, A., Sandahl, I., Nozawa, S., and Fujii, R.: Coordinated EISCAT Svalbard radar and Reimei satellite observations of ion upflows and suprathermal ions, J. Geophys. Res. (Space Physics), 113, 5306, doi:10.1029/2007JA012791, 2008.

Oliver, W. L.: Incoherent scatter radar studies of the daytime middle thermosphere, Annales de Geophysique, 35, 121-139, 1979.

Oliver, W. L. and Glotfelty, K.: $\mathrm{O}^{+}-\mathrm{O}$ collision cross section and long-term $\mathrm{F}$ region $\mathrm{O}$ density variations deduced from the ionospheric energy budget, J. Geophys. Res., 101, 21769-21784, doi: 10.1029/96JA01585, 1996.

Opgenoorth, H. J., Haggstrom, I., Williams, P. J. S., and Jones, G. O. L.: Regions of strongly enhanced perpendicular electric fields adjacent to auroral arcs, J. Atmos. Terr. Phys., 52, 449458, 1990.

Oyama, S., Lathuillere, C., Maeda, S., and Watkins, B. J.: Summerwinter dependences of day-night differences in the ion temperature in the polar upper F region, Geophys. Res. Lett., 31, 5806, doi:10.1029/2003GL018820, 2004.
Peterson, W. K., Abe, T., Fukunishi, H., Greffen, M. J., Hayakawa, H., Kasahara, Y., Kimura, I., Matsuoka, A., Mukai, T., and Nagatsuma, T.: On the sources of energization of molecular ions at ionospheric altitudes, J. Geophys. Res., 99, 23257-23274, 1994.

Picone, J. M., Hedin, A. E., Drob, D. P., and Aikin, A. C.: NRLMSISE-00 empirical model of the atmosphere: Statistical comparisons and scientific issues, J. Geophys. Res. (Space Physics), 107, 1468, doi:10.1029/2002JA009430, 2002.

Raman, R. S. V., St-Maurice, J. P., and Ong, R. S. B.: Incoherent scattering of radar waves in the auroral ionosphere, J. Geophys. Res., 86, 4751-4762, doi:10.1029/JA086iA06p04751, 1981.

Richmond, A. D. and Lu, G.: Upper-atmospheric effects of magnetic storms: a brief tutorial, J. Atmos. Solar-Terr. Phys., 62, 1115-1127, doi:10.1016/S1364-6826(00)00094-8, 2000.

Rino, C. L., Baron, M. J., and Brekke, A.: High-resolution auroral zone $\mathrm{E}$ region neutral wind and current measurements by incoherent scatter radar, J. Geophys. Res., 82, 2295-2304, doi: 10.1029/JA082i016p02295, 1977.

Rodger, A. S., Moffett, R. J., and Quegan, S.: The role of ion drift in the formation of ionisation troughs in the mid- and high-latitude ionosphere - A review, J. Atmos. Terr. Phys., 54, 1-30, 1992.

Salah, J. E.: Interim standard for the ion-neutral atomic oxygen collision frequency, Geophys. Res. Lett., 20, 1543-1546, doi: 10.1029/93GL01699, 1993.

Schlegel, K. and St.-Maurice, J. P.: Anomalous heating of the polar E region by unstable plasma waves. I - Observations, J. Geophys. Res., 86, 1447-1452, 1981.

Schunk, R. W. and Nagy, A.: Ionospheres, Cambridge University Press, Cambridge, 2000.

Schunk, R. W., Banks, P. M., and Raitt, W. J.: Effect of electric fields on the daytime high-latitude $\mathrm{E}$ and $\mathrm{F}$ regions, J. Geophys. Res., 80, 3121-3130, 1975.

Semeter, J., Heinselman, C. J., Thayer, J. P., and Doe, R. A.: Ion upflow enhanced by drifting F-region plasma structure along the nightside polar cap boundary, Geophys. Res. Lett., 22, 2139, doi:10.1029/2003GL017747, 2003.

Semeter, J., Heinselman, C. J., Sivjee, G. G., Frey, H. U., and Bonnell, J. W.: Ionospheric response to wave-accelerated particles at the poleward auroral boundary, J. Geophys. Res., 110, A11310, doi:10.1029/2005JA011226, 2005.

Shibata, T., Matsuya, H., and Hoashi, J.: Ion Composition in the Auroral Lower F-Region Inferred from Residuals of Ion Temperature Profiles Observed with EISCAT, Adv. Space Res., 25, 201-210, doi:10.1016/S0273-1177(99)00919-9, 2000.

St.-Maurice, J.-P. and Hanson, W. B.: Ion frictional heating at high latitudes and its possible use for an in situ determination of neutral thermospheric winds and temperatures, J. Geophys. Res., 87, 7580-7602, 1982.

St.-Maurice, J.-P. and Laneville, P. J.: Reaction rate of $\mathrm{O}^{+}$with $\mathrm{O}_{2}, \mathrm{~N}_{2}$, and NO under highly disturbed auroral conditions, J. Geophys. Res., 103, 17519-17522, 1998.

St-Maurice, J.-P. and Schunk, R. W.: Auroral ion velocity distributions for a polarization collision model, Planet. Space Sci., 25, 243-260, doi:10.1016/0032-0633(77)90135-0, 1977.

St-Maurice, J.-P. and Schunk, R. W.: Ion velocity distribution in the high-latitude ionosphere., Rev. Geophys. Space Phys., 17, 99134, 1979.

St.-Maurice, J.-P. and Schunk, R. W.: Ion-neutral momentum coupling near discrete high-latitude ionospheric features, J. Geo- 
phys. Res., 86, 11 299-11 321, 1981.

St.-Maurice, J.-P. and Torr, D. G.: Nonthermal rate coefficients in the ionosphere - The reactions of $\mathrm{O} /+/$ with $\mathrm{N} 2, \mathrm{O} 2$, and $\mathrm{NO}$, J. Geophys. Res., 83, 969-977, doi:10.1029/JA083iA03p00969, 1978.

St.-Maurice, J.-P., Cussenot, C., and Kofman, W.: On the usefulness of $\mathrm{E}$ region electron temperatures and lower $\mathrm{F}$ region ion temperatures for the extraction of thermospheric parameters: a case study, Ann. Geophys., 17, 1182-1198, 1999, http://www.ann-geophys.net/17/1182/1999/.

Stasiewicz, K., Bellan, P., Chaston, C., Kletzing, C., Lysak, R., Maggs, J., Pokhotelov, O., Seyler, C., Shukla, P., Stenflo, L., Streltsov, A., and Wahlund, J.-E.: Small Scale Alfvénic Structure in the Aurora, Space Sci. Rev., 92, 423-533, 2000.

Streltsov, A. V. and Lotko, W.: Multiscale electrodynamics of the ionosphere-magnetosphere system, J. Geophys. Res. (Space Physics), 109, 9214, doi:10.1029/2004JA010457, 2004.

Streltsov, A. V. and Lotko, W.: Coupling between density structures, electromagnetic waves and ionospheric feedback in the auroral zone, J. Geophys. Res. (Space Physics), 113, 5212, doi: 10.1029/2007JA012594, 2008.

Thayer, J. P.: Height-resolved Joule heating rates in the highlatitude $\mathrm{E}$ region and the influence of neutral winds, J. Geophys. Res., 103, 471-487, doi:10.1029/97JA02536, 1998.
Torr, M. R., Torr, D. G., and Saint-Maurice, J. P.: The rate coefficient for the $\mathrm{O}^{+}+\mathrm{N}_{2}$ reaction in the ionosphere, J. Geophys. Res., 82, 3287-3290, 1977.

Waldteufel, P.: Combined Incoherent-Scatter F1-Region Observations, J. Geophys. Res., 76, 6995-6999, doi:10.1029/ JA076i028p06995, 1971.

Wilson, G. R. and Craven, P.: Molecular ion upflow in the cleft ion fountain, J. Geophys. Res., 104, 4437-4446, doi:10.1029/ 1998JA900070, 1999.

Winkler, E., St.-Maurice, J.-P., and Barakat, A. R.: Results from improved Monte Carlo calculations of auroral ion velocity distributions, J. Geophys. Res., 97, 8399-8423, 1992.

Yau, A. W., Whalen, B. A., Goodenough, C., Sagawa, E., and Mukai, T.: EXOS D (Akebono) observations of molecular $\mathrm{NO}(+)$ and $\mathrm{N} 2(+)$ upflowing ions in the high-altitude auroral ionosphere, J. Geophys. Res., 98, 11205, 1993.

Zettergren, M., Semeter, J., Blelly, P.-L., and Diaz, M.: Optical estimation of auroral ion upflow: Theory, J. Geophys. Res., 112, A12310, doi:10.1029/2007JA012691, 2007.

Zettergren, M., Semeter, J., Blelly, P.-L., Sivjee, G., Azeem, I., Mende, S., Gleisner, H., Diaz, M., and Witasse, O.: Optical estimation of auroral ion upflow: 2. A case study, J. Geophys. Res. (Space Physics), 113, 7308, doi:10.1029/2008JA013135, 2008. 